\title{
A RESEARCH ON OPERATIONAL PATTERNS IN CONTAINER LINER SHIPPING
}

\author{
Nguyen Khoi TRAN ${ }^{*}$, Hans-Dietrich HAASIS \\ Faculty of Business Studies and Economics, University of Bremen, Germany
}

Received 5 August 2015; revised 3 February 2016, 23 May 2016; accepted 31 May 2016

\begin{abstract}
This article studies operational patterns in container liner shipping with the emphasis on End-To-End (ETE), Round-The-World (RTW), and pendulum patterns. The first research issue deals with their deployment on designing shipping routes on the East-West corridor. The second issue compares their operational characteristics to realize their strength and weakness. The empirical work is carried out using 2074 route records of the top 20 shipping lines from 1995 to 2011. During the period, ETE was the dominant pattern. From 81 to $93 \%$ of the surveyed routes operated under this pattern. Pendulum was in favour in the early 2000s, but its use later declined. Round the world had been expected as an innovation in the industry but it was employed limitedly. An important feature of RTW and pendulum patterns is to include multiple trades on a single route, which can bring about the advantages of traffic bundling and less fleet requirement. On the other hand, multiple trades result in more complexity of these patterns, displayed through long voyage distance and time, a greater number of visited regions and more ports of call. Additionally, the deployment of mega vessels is also restricted due to traffic discrepancy between trade lanes.
\end{abstract}

Keywords: maritime transport geography, container liner shipping, operational pattern, end-to-end, round-the-world, pendulum.

\section{Introduction}

Container liner shipping can be considered as a networkbased industry. Its operation greatly depends on the design of shipping networks, formed by various routes. There are many network issues, which have attracted much attention from the research community, for instance: network optimisation (Tran et al. 2017; Chen, Zeng 2010); ship deployment (Lim 1994; Cullinane, Khanna 2000); network analysis (Ducruet 2013; Tran, Haasis 2014); regional shipping network (Fremont 2007; Robinson 1998). This article concentrates on operational patterns, an issue with little consideration in the market.

Basic operational patterns of container liner shipping consist of Hub-And-Spoke (H\&S), End-To-End (ETE), Round-The-World (RTW), pendulum and triangle (Angeloudis et al. 2007; Dynamar 2007; Ma 2006; Slack 1999). The H\&S is the base for the transportation system whereby different routes are combined through transhipment activities to expand the coverage of shipping services. The other four patterns determine route configuration and depict how ships on a loop travel between trade regions.
Almost all studies involving the operational patterns have been involved with the H\&S, for example: regional H\&S system (Gouvernal et al. 2005; Wang, Slack, 2000); viability of transhipment hubs (Baird 2006; Fleming 2010; McCalla 2008); optimal system (Aversa et al. 2005; Gelareh et al. 2013; Imai et al. 2006); interlining and relay hubs (De Monie 2001; Notteboom 2012; Rodrigue et al. 2009).

In contrast, not many works deal with other patterns. Different variants of route configurations deployed in the 1980s are described by Pearson and Fossey (1983). Formerly considered as a major innovation in liner shipping, the RTW pattern has attracted significant interest from researchers to evaluate its operational, commercial and economic aspects as well as success and failure of users (Gielessen 1991; Kim 1987; Drewry 1986; Lloyd's List 1994; Container Insight 1988; Lim 1996). Cost comparisons between the ETE, RTW and pendulum patterns are carried out by Lim (1996) and Pearson and Fossey (1983). Fleming (2010) compares the three patterns in serving the global market regarding geographical constraints, de-

*Corresponding author. E-mails: khoi.tran@uni-bremen.de,trannguyenkhoi@gmail.com 
ployed vessel size, traffic potential and empty container repositioning. Ashar $(1999,2000,2002)$ analyses inherent deficiency of the patterns used in practice and propose a new equatorial RTW pattern to restructure the container shipping system. Visser and Braam (2001) also suggest a backbone system, using mega ships and a few hubs along the equatorial axis to transport the world-wide traffic. Whereas the model of Ashar $(1999,2000,2002)$ is based on the RTW pattern, their model is on the basis of the pendulum pattern.

The shortage of literature on route configuration encourages us to explore deeply into the field. Two key issues are carried out in this research. The first one is the application of the operational patterns on designing transcontinental East-West shipping routes. The second one is a comparative analysis between ETE, RTW and pendulum routes regarding number of visited regions, ports of call, transit time, route complexity, and ship deployment to have a better view about characteristics of each pattern. The empirical work is based on the service data of the top 20 shipping lines between 1995 and 2011, published in Containerisation International Yearbooks (CI 1996-2012).

This paper is structured as follows. Section 1 provides a description of the operational patterns. Section 2 focuses on their deployment in shipping operation. Section 3 addresses a comparative analysis between route patterns. The last section includes some conclusions.

\section{Review of operational patterns}

\subsection{Hub and spoke (H\&S)}

This pattern plays a key role not only in container liner shipping but also in other transportation modes. It stems from the model pioneered by Federal Express in the 1970s whereby all packages from different sources are collected through a central hub, then distributed to their destinations (Dynamar 2007). The H\&S benefits operators in terms of density economies by providing more frequent services, scale economies by deploying larger transport means, and scope economies by joining freight from different routes (Konings 2006).

It is the fact that a route cannot cover all ports in a region. A port may be ignored because it cannot provide adequate traffic to justify a direct call, or it is far from the arterial passage, or lacks of natural and operating conditions to handle big vessels. Moreover, economics of ship size also restricts the number of stops on a string (Gilman 1999; Tran 2011). As a consequence, carriers must rely on the H\&S to ensure the efficiency of intercontinental shipping as well as to maintain their market coverage. Several ports are selected as hubs. They are directly visited by mother vessels and are transhipment points for boxes to/ from their surrounding areas thanks to feeder services. An ideal hub is situated close to the gravity centre of regional demand so that detour distance and transport time can be minimised (Vrenken et al. 2005).
In addition to being a feedering centre, a hub can also act as an interlining or relay centre. In the interlining function containers that bypass ports are transhipped at the regional hub. Afterwards, they are transported to their destinations by mainline vessels, not by feeder ones as in the traditional function. The variant permits two ETE services to operate effectively as four services (Sutcliffe, Ratcliffe 1995). More ports can be served without lengthening mother ships' itinerary. In relay function, operators can extend service coverage and flexibility by linking EastWest and North-South loops operating in different directions (Stenvert, Penfold 2007). Containers are switched between trunk ships and delivered to their destinations, which are not in the same region as the transhipment hub (Figure 1). For instance, a box from North East Asia (NEA) to Australasia could be first shipped by a NEA North Europe route; then transhipped in Singapore and carried to the customer by a South East Asia - Australasia route. The relay system based on some strategic hubs is claimed to successfully facilitate the global coverage of Zim in the 1990s, though the Israeli carrier only provided a smaller number of routes (Gardiner 1998).

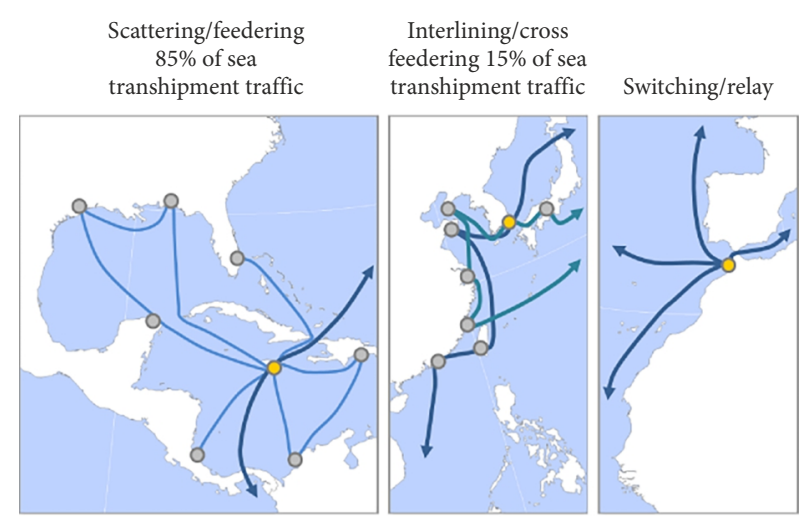

Figure 1. Transhipment functions (Rodrigue et al. 2009)

According to UNCTAD's Liner Shipping Connectivity Index (UNCTAD 2009), 17.2\% of pairs of countries could be linked by direct liner shipping services; $62 \%$ by one transhipment; $18.6 \%$ by two transhipments; and for the remaining $2.2 \%$ by three transhipments. Container shipping must depend substantially on the H\&S system to ensure the global coverage. The continual growth of transhipment operation has been noted. The average number of transfers between ship and shore was 2.0 in 1960, up to 2.9 in 1980, 3.2 in 2000 and 3.5 in 2012 based on Frankel (2004) and Drewry (2013). The worldwide transhipment handling volume increased more than 40 -fold between 1980 and 2012, from 4.2 to $174.6 \mathrm{~m}$ TEUs (Drewry 2013). The transhipment incidence also moved up from 11 to $28 \%$.

\subsection{End-To-End (ETE)}

ETE is the most common pattern in container shipping. Most intercontinental routes, whether they serve EastWest or North-South trades, follow this pattern (Dynamar 
2007). Basically, ETE ships sail back and forth between two continents. ETE routes are not complicated, relatively easy to organize and do not require high investment.

The simplest form of this pattern is displayed in Figure 2 , in which containers are only carried between two regions. Routes to serve the Trans-Atlantic and Trans-Pacific trades often fall into this form. Another variant is to link more than two regions on a single loop. For instance, the North Europe - NEA service in Figure 3 goes through the intermediate regions of South East Asia and the Middle East. Routes between NEA and East Coast North America may also serve the port ranges of West Coast North America, and Central America and the Caribbean.

The third variant is a combination of two or three simple ETE routes servicing the same trade lane into a single one. It has been not popular in the industry with only one or two services on the Trans-Atlantic or TransPacific lane in yearly operation. In Figure 4, the butterfly service is similar to two ETE ones. They both operate on the Trans-Atlantic corridor with the overlap in the North European port range, whereas the ranges in East Coast North America are different: (New York, Norfolk) and (Charleston, Miami, Houston). Instead of operating independently, they are integrated through the overlapping ports. In practice, such butterfly route has required fewer deployed ships than two separate routes (Drewry 2000; SOL 2008; Chineseshipping 2011). The saving is attributable to shorter total time spent in port ranges.

\subsection{Round-The-World (RTW)}

RTW is the only pattern directing ship movement in either westbound or eastbound direction (Figure 5). A ship circumnavigates the world and travels along the East-West axis through major strategic maritime passages. It attempts to serve the three key trade lanes of Trans-Atlantic, TransPacific and Europe - East Asia on a single trip.

In 1984, the first RTW services were inaugurated by Evergreen and United States Lines (USL). They expected cost advantage from the breakthrough to escape from cutthroat rate wars in the market (Drewry 1986). However, only Evergreen had succeeded in the new pattern. The demise of the RTW strategy forced USL to file for bankruptcy at the end of 1986. Some pronounced mistakes of USL include (Gibney 1987; Knee 1987; Lim 1996; Willmington 2004):

- inflexibility in terms of cargo (serves only 40 foot containers), routing (only eastbound) and large ship size;

- low speed;

- bad service quality;

- market miscalculation.

Besides the traditional RTW services like those of Evergreen and USL, there have been secondary RTW ones passing through Australasia (Figure 6). On the loops, ships travel not only along the East-West axis, but also NorthSouth on some legs. For example, in 2004, the RTW route jointly operated by P\&O Nedlloyd, CMA-CGM and CP Ships (ANZ Westabout) made a global tour via Europe,

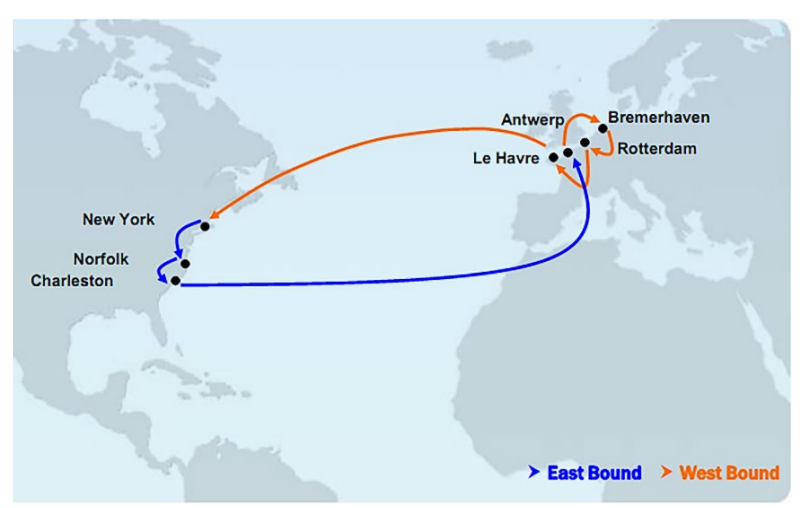

Figure 2. Simple ETE service (Hanjin Shipping 2016)

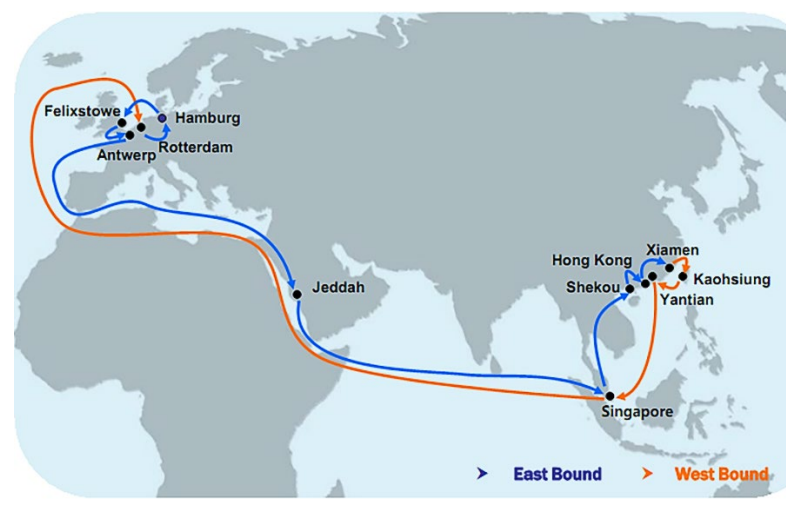

Figure 3. ETE service with intermediate regions (Hanjin Shipping 2016)

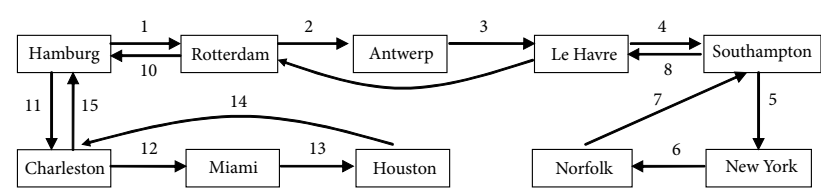

Figure 4. Butterfly route

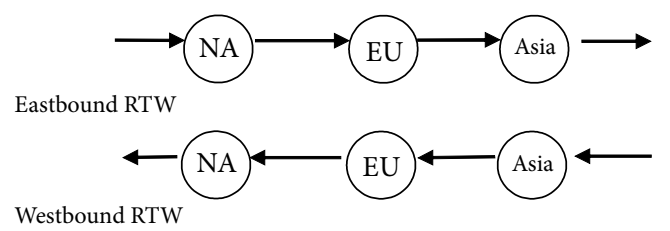

Figure 5. RTW models (NA - North America; EU - Europe)

East Coast North America, Australasia and South East Asia. In 2006, CMA-CGM organized a RTW loop (RTW Pan) to call the three former markets.

\subsection{Pendulum}

This pattern is also known as 'figure-of-eight' or 'double loop' (Gardiner 1998). It has gone into operation since the 1970 s by an Israeli operator Zim. Another pioneer is a Taiwanese carrier Yangming, which kicked off a service in the second half of the 1980s. A pendulum route is a combination of two or three ETE ones operating on different trade lanes. It aims to serve the three continents as a RTW 


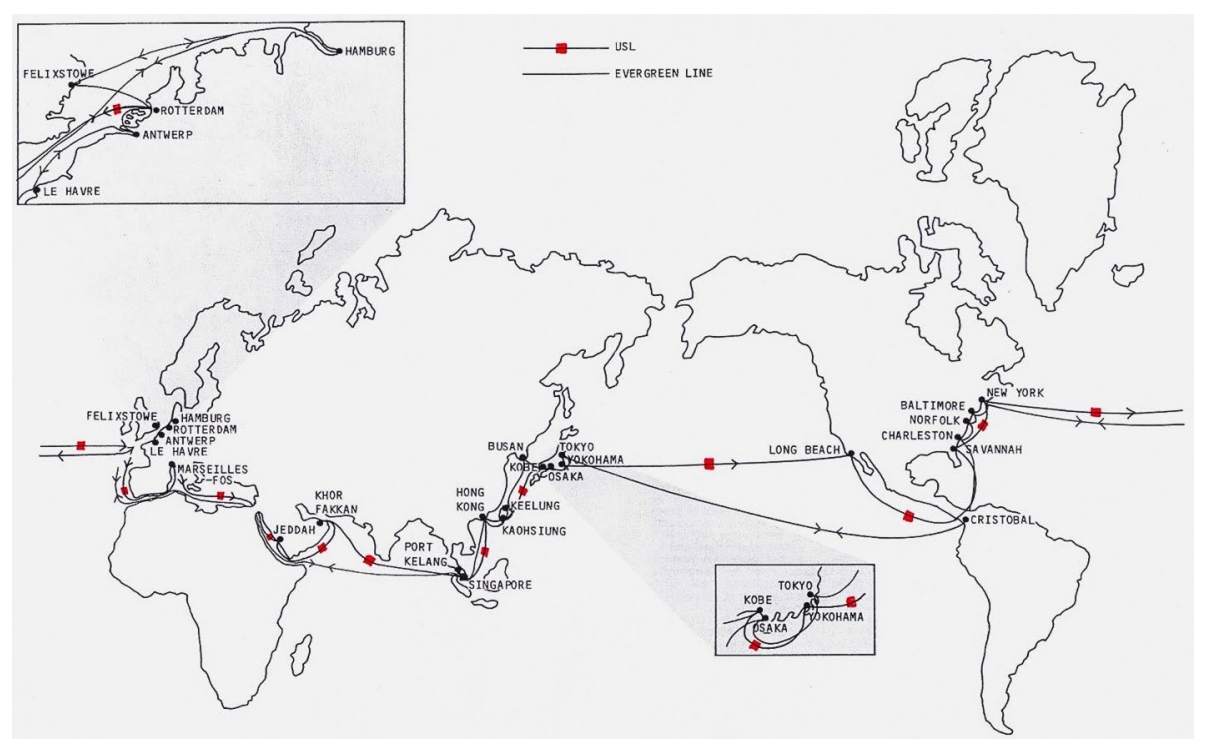

Figure 6. The RTW routes of USL and Evergreen (Drewry 1986)

route, but the ship travels both eastwards and westwards, not only by one direction. Additionally, one key leg on the East-West axis is often absent from the ships' itinerary.

Following the pendulum, a ship moves between the three continents of Asia, Europe and North America, one of which plays a role as the middle market or as the fulcrum of the loop. As a pendulum, the ship swings to either side of the fulcrum to serve the two remaining markets. An operator could depend upon strongly captured traffic in the fulcrum to secure the service. Yangming's strategy was to utilise the key cargo base in Taiwan, representing up to $40 \%$ of its liftings, to develop its first pendulum service in the 1980s (Boyes 1985).

In Figure 7, the ships cross over the Pacific Ocean from East Asia to West Coast, then East Coast North America. Afterwards, they traverse the Atlantic Ocean to the Mediterranean Sea, turn around and return to the fulcrum North American, then end up in East Asia to complete a cycle. The ships operate between East Asia and the Mediterranean Sea via the Panama Canal. They transport containers on the Trans-Atlantic and Trans-Pacific corridors, whereas the Mediterranean Sea - East Asia one is excluded from their voyage. Such service is not affected by any vulnerability of the Suez Canal (Pearson, Fossey 1983), but suffers from the ship size restriction of the Panama Canal.

Based on the middle market, three major pendulum models can be classified. An extension of the pendulum, named horse-shoe shaped model (Pearson, Fossey 1983), comprises all the key legs on a string. This grand pendulum loop swings between East Coast and West Coast North America through the two fulcrums of Europe and Asia. Because the Panama Canal is excluded from the ship journey, the service could avoid the trade restriction between the US West Coast and East Coast as well as nautical limitation of the canal (Figure 8).

The pendulum pattern is employed not only on the East-West corridor, but also on the North-South one. To such an extent, it may include secondary markets in Australasia, Africa and South America. For example, loops are designed to link Europe, South Africa (fulcrum) and Australasia, or East Asia, South Africa (fulcrum) and South America.

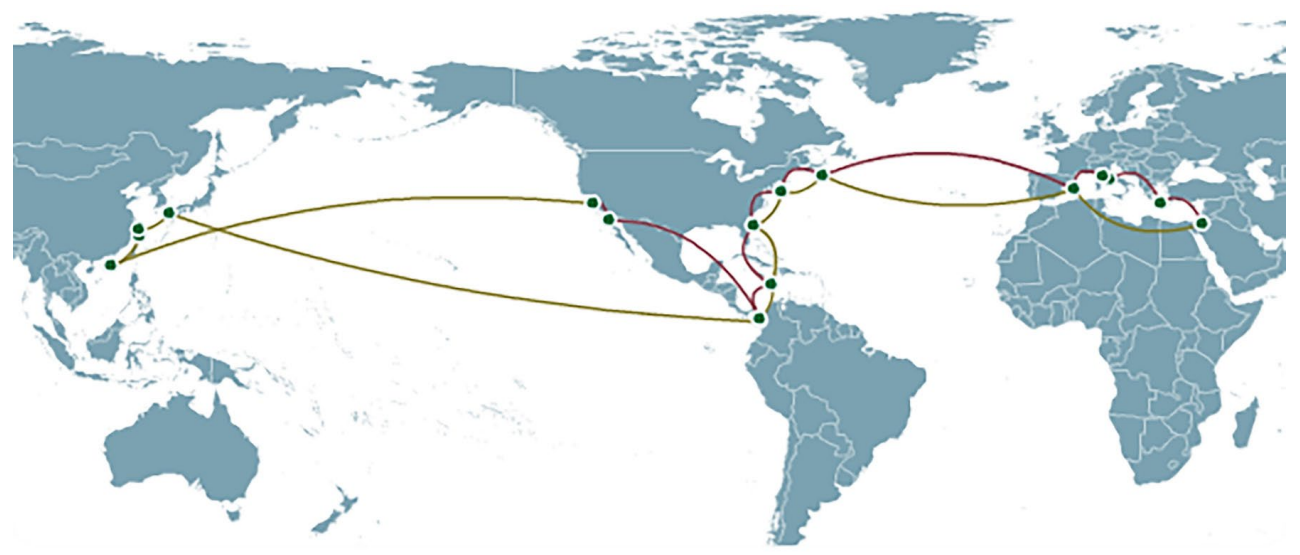

Figure 7. Zim's pendulum route in 2011 (ZIM 2016) 


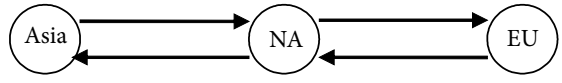

Pendulum 1 (North America as the middle market)

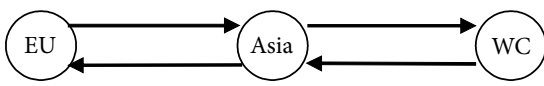

Pendulum 3 (Asia as the middle market)

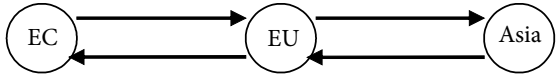

Pendulum 2 (Europe as the middle market)

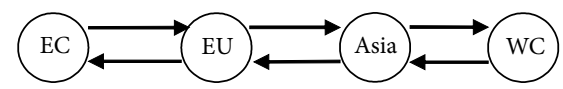

Pendulum 4 (Europe and Asia as the middle markets)

Figure 8. Pendulum models (NA - North America; EU - Europe; WC - West Coast; EC - East Coast)

\subsection{Triangle}

This pattern links three markets in one way. It aims to counteract trade imbalance by focusing on denser traffic directions between markets to improve ship slot filling factor. For instance, on a typical triangle route (North Europe $\rightarrow$ Australasia $\rightarrow$ South East Asia $\rightarrow$ North Europe), operators exploit volume dominance of the southbound leg from Europe to Australasia, and the westbound one from South East Asia to Europe. The triangle pattern is almost as old as international shipping (Pearson, Fossey 1983) and employed a lot in tramp shipping, which often suffers seriously from trade imbalance. However, its use in liner shipping is not common and only limited in minor trades or applied by carriers, who can combine containers with other bulk cargoes. The selection of three optimal traffic flows to launch a feasible triangle route can be rather sophisticated.

\section{Deployment of operational patterns}

\subsection{Data description}

This article aims to study operational patterns of intercontinental routes on the East-West axis. The routes link markets in the three continents of North America, Europe and Asia. Data is retrieved from 2074 service records of the top 20 shipping lines in the years 1995-2011, published by Containerisation International Yearbooks (CI 1996-2012). Basic features of a service consist of port rotation, arrival schedule, ship fleet and operators. From the collected data, it can determine other information related to the shipping service: trade regions of call as well as their order on the loop, operational pattern deployed, transit time between ports, route length, fleet capacity and the number of weekly calls (Table 1 ).

\subsection{Results}

The East-West shipping (Figure 9) volume climbed significantly from $15.41 \mathrm{~m}$ TEUs in 1995 to $35.35 \mathrm{~m}$ TEUs in 2003 and $68.61 \mathrm{~m}$ TEUs in 2011 (Drewry 2000, 2004, 2012). It accounted for $42.1 \%$ of the global volume in 2011. Being the first international container shipping corridor, but North America - Europe has been left far behind by North America - Asia and Europe - Asia in terms of shipping traffic. From 1995 to 2011, its traffic went up by only 1.8 times (from $3.47 \mathrm{~m}$ to $6.24 \mathrm{~m}$ TEUs) in comparison with 3.18 times $(7.51 \mathrm{~m}$ to $23.9 \mathrm{~m}$ TEUs) of the second and 5.84 times (4.44m to $25.93 \mathrm{~m}$ TEUs) of the latter corridors. During this period, the Europe - Asia traffic experienced the greatest boom. It even overcame the North America - Asia traffic from 2006. Intra-regional trades between East Asia, South Asia, and the Middle East also underwent substantial surge from $1.7 \mathrm{~m}$ TEUs in 1999 to $12.6 \mathrm{~m}$ TEUs in 2011. These shipping flows could be served not only by intra-regional but also by trans-continental Europe - Asia routes.

New trans-continental routes and vessel fleet were added to the transportation system in harmony with the growth of the East-West traffic. The system developed from 96 routes (the fleet of $1.48 \mathrm{~m}$ TEUs) in 1995 to 123 routes ( $3.52 \mathrm{~m}$ TEUs) in 2003 and 132 routes (6.5m TEUs)

Table 1. Information of a shipping service (CI 2012)

Service name: APX
Operators: APL and MOL
Year in operation: 2011
Port rotation: Chiwan (arrival day 0); Hong Kong (1); Kaohsiung (2); Busan (5); Kobe (7); Tokyo (8); Balboa (24); Puerto
Manzanillo (25); Miami (29); Jacksonville (30); Savannah (31); Charleston (32); New York (34); Antwerp (43); Felixstowe (44);
Bremerhaven (45); Rotterdam (47); Le Havre (49); New York (56); Norfolk (57); Charleston (59); Puerto Manzanillo (63); Balboa
(64); San Pedro (72); Oakland (74); Tokyo (86); Kobe (87); Chiwan (91)
Regions of call: NEA $\rightarrow$ Central America and the Caribbean $\rightarrow$ East Coast North America $\rightarrow$ North Europe $\rightarrow$ East Coast North
America $\rightarrow$ Central America and the Caribbean $\rightarrow$ West Coast North America $\rightarrow$ NEA
Operational pattern: Pendulum, with the middle market of North America, side markets of NEA and North Europe
Number of ships: 13 ; Total fleet capacity: 60889 TEUs; Average ship size: 4684 TEUs
Route length: 32269 miles; Voyage time: 91 days; Number of weekly calls: 27


in 2011. The breakdown of shipping routes, deployed fleet, and the number of weekly calls based on operational patterns bears out the domination of the ETE in route configuration in the years 1995-2011 (Table 2). From 81 to $93 \%$ of transcontinental routes on the East-West axis operated under the pattern. Their portions in the combined fleet capacity and total calls were in the ranges from 68 to $92 \%$ and from 68 to $89 \%$, respectively.

Along the East-West axis, 9 key trade regions are categorized: West Coast North America, Central America and the Caribbean, East Coast North America, North Europe, the Mediterranean Sea, the Middle East, South Asia, South East Asia, and NEA. 132 different configurations linking regions between two continents are collected. Based on the easternmost and westernmost regions, they can be classified into 19 ETE route segments to serve
East-West trans-continental traffic. Their deployment on the shipping system is illustrated in Figure 10.

In the years 1995-2011, NEA - West Coast North America, East Coast North America - North Europe and North Europe - NEA routes were the most important ETE ones on the Trans-Atlantic, Europe - Asia and Trans-Pacific corridors. Altogether, they often accounted for more than $50 \%$ of the combined East-West routes and fleet capacity. Furthermore, it could be observed the great upgrading of East Coast North America - Mediterranean routes, Mediterranean - NEA and North Europe - South Asia routes, and NEA - East Coast North America routes via the Panama Canal to adapt to the upswing of shipping demand.

The North Europe - NEA and NEA - East Coast North America routes were often the longest ETE ones

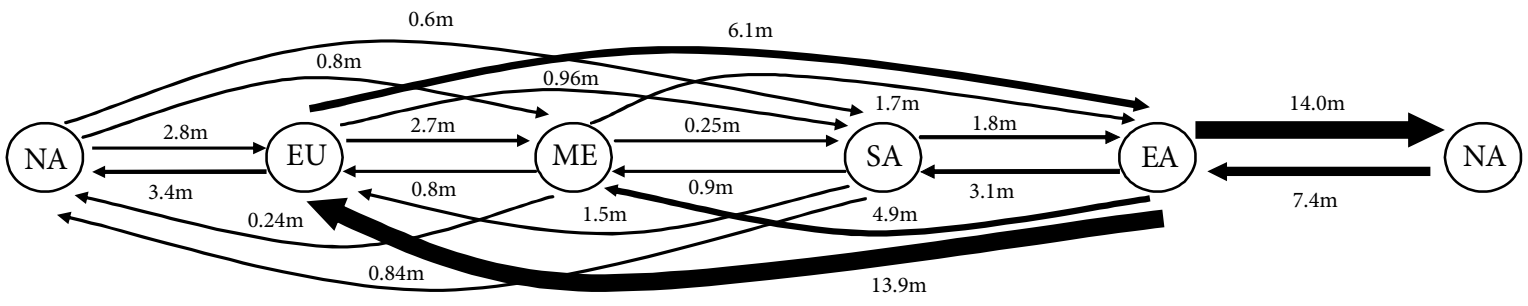

Figure 9. The East-West shipping flows (unit - TEUs; NA - North America; EU - Europe; ME - Middle East; SA - South Asia; EA - East Asia) (Drewry 2012)
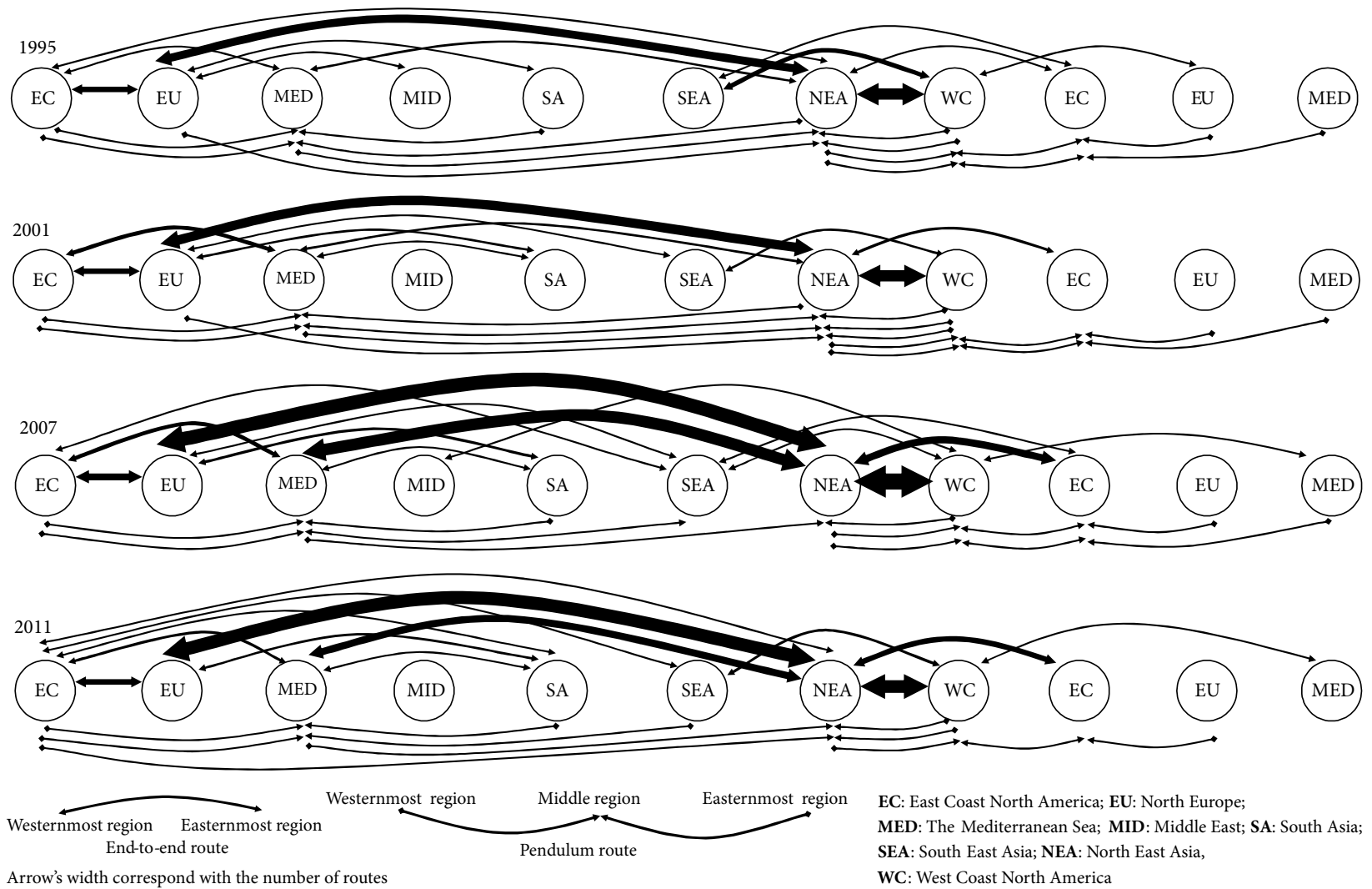

Figure 10. ETE and pendulum routes on the shipping network (EC - East Coast North America; EU - North Europe; MED - Mediterranean Sea; MID - Middle East; AS - South Asia; SEA - South East Asia; NEA - North East Asia; WC - West Coast North America) 
with the length of over 23000 miles (Table 3). From 2009, some longer routes above 27000 miles were designed to connect NEA and East Coast North America via the Suez Canal. Compared with the routes via the Panama Canal, the new routes suffer from longer travelling journey, but are advantageous in terms of no ship size restriction and high potential for collecting goods from the intermediate markets of South East Asia, South Asia and the Middle East.

Table 2. Breakdown of routes, deployed fleet and weekly calls by operational patterns

\begin{tabular}{|c|c|c|c|c|c|c|c|c|c|c|c|c|c|c|c|}
\hline & \multicolumn{5}{|c|}{ Number of routes } & \multicolumn{5}{|c|}{ Deployed fleet (1000 TEUs) } & \multicolumn{5}{|c|}{ Number of weekly calls } \\
\hline & ETE & $\mathrm{PDL}$ & RTW & TRI & Total & ETE & PDL & RTW & TRI & Total & ETE & PDL & RTW & TRI & Total \\
\hline 1995 & 83 & 9 & 4 & 0 & 96 & 1138 & 201 & 140 & 0 & 1480 & 867 & 169 & 74 & 0 & 1110 \\
\hline 1996 & 93 & 7 & 4 & 0 & 104 & 1219 & 209 & 117 & 0 & 1545 & 924 & 134 & 72 & 0 & 1130 \\
\hline 1997 & 78 & 10 & 2 & 0 & 90 & 1330 & 366 & 85 & 0 & 1782 & 812 & 202 & 39 & 0 & 1053 \\
\hline 1998 & 71 & 11 & 2 & 0 & 84 & 1415 & 430 & 87 & 0 & 1932 & 768 & 225 & 39 & 0 & 1032 \\
\hline 1999 & 80 & 12 & 2 & 0 & 94 & 1497 & 514 & 78 & 0 & 2089 & 835 & 249 & 38 & 0 & 1122 \\
\hline 2000 & 90 & 12 & 2 & 1 & 105 & 1814 & 615 & 79 & 12 & 2521 & 939 & 262 & 40 & 6 & 1247 \\
\hline 2001 & 90 & 13 & 2 & 1 & 106 & 2100 & 728 & 83 & 6 & 2917 & 928 & 280 & 38 & 7 & 1253 \\
\hline 2002 & 82 & 18 & 0 & 1 & 101 & 2111 & 971 & 0 & 12 & 3093 & 855 & 392 & 0 & 7 & 1254 \\
\hline 2003 & 109 & 13 & 0 & 1 & 123 & 2815 & 693 & 0 & 16 & 3524 & 1113 & 286 & 0 & 7 & 1406 \\
\hline 2004 & 123 & 12 & 1 & 2 & 138 & 3261 & 667 & 35 & 51 & 4014 & 1235 & 248 & 18 & 16 & 1517 \\
\hline 2005 & 139 & 10 & 2 & 2 & 153 & 3948 & 541 & 74 & 63 & 4626 & 1348 & 207 & 37 & 16 & 1608 \\
\hline 2006 & 143 & 11 & 2 & 3 & 159 & 4313 & 571 & 81 & 98 & 5063 & 1368 & 213 & 41 & 22 & 1644 \\
\hline 2007 & 153 & 14 & 0 & 1 & 168 & 4853 & 672 & 0 & 31 & 5556 & 1454 & 253 & 0 & 9 & 1716 \\
\hline 2008 & 143 & 15 & 0 & 1 & 159 & 5014 & 806 & 0 & 30 & 5849 & 1415 & 281 & 0 & 9 & 1705 \\
\hline 2009 & 110 & 12 & 2 & 0 & 124 & 4513 & 752 & 83 & 0 & 5348 & 1229 & 226 & 21 & 0 & 1476 \\
\hline 2010 & 125 & 12 & 1 & 0 & 138 & 5411 & 762 & 42 & 0 & 6216 & 1395 & 231 & 14 & 0 & 1640 \\
\hline 2011 & 123 & 8 & 1 & 0 & 132 & 5991 & 457 & 55 & 0 & 6503 & 1328 & 153 & 16 & 0 & 1497 \\
\hline
\end{tabular}

Notes: ETE - end-to-end; PDL - pendulum; RTW - round-the-world; TRI - triangle.

Table 3. Operational parameters of major ETE routes

\begin{tabular}{|c|c|c|c|c|c|c|c|c|c|c|c|c|}
\hline & \multicolumn{4}{|c|}{ ECNA - North Europe } & \multicolumn{4}{|c|}{ NEA - WCNA } & \multicolumn{4}{|c|}{ North Europe - NEA } \\
\hline & Route & Time & Length & Size & Route & Time & Length & Size & Route & Time & Length & Size \\
\hline 1995 & 12 & & 9533 & 2806 & 25 & & 12950 & 2905 & 18 & & 23598 & 3443 \\
\hline 1997 & 12 & & 9639 & 2747 & 21 & & 13431 & 3409 & 18 & & 23453 & 3863 \\
\hline 1999 & 15 & & 9516 & 2617 & 22 & & 13079 & 3417 & 18 & & 23404 & 4085 \\
\hline 2001 & 12 & 28 & 9405 & 2826 & 25 & 34 & 13047 & 3729 & 21 & 57 & 23459 & 4918 \\
\hline 2003 & 11 & 28 & 9229 & 3335 & 33 & 34 & 13010 & 3970 & 20 & 58 & 23606 & 5657 \\
\hline 2005 & 12 & 28 & 9205 & 3246 & 42 & 34 & 12708 & 4489 & 30 & 57 & 23123 & 5957 \\
\hline 2007 & 15 & 28 & 9374 & 3360 & 40 & 33 & 12672 & 4945 & 31 & 58 & 23059 & 7255 \\
\hline 2009 & 10 & 31 & 9403 & 3632 & 28 & 35 & 12877 & 5732 & 26 & 65 & 23708 & 8378 \\
\hline \multirow[t]{3}{*}{2011} & 12 & 32 & 9706 & 3930 & 28 & 37 & 12520 & 6341 & 29 & 70 & 23371 & 9188 \\
\hline & \multicolumn{4}{|c|}{ ECNA - MED } & \multicolumn{4}{|c|}{ NEA - ECNA } & \multicolumn{4}{|c|}{ MED - NEA } \\
\hline & Route & Time & Length & Size & Route & Time & Length & Size & Route & Time & Length & Size \\
\hline 1995 & 2 & & 9672 & 1662 & 3 & & 23577 & 3081 & 5 & & 19111 & 2083 \\
\hline 1997 & 7 & & 11325 & 1225 & 4 & & 23602 & 3331 & 4 & & 19343 & 2223 \\
\hline 1999 & 4 & & 10224 & 1600 & 4 & & 23886 & 3014 & 5 & & 20294 & 3219 \\
\hline 2001 & 9 & 32 & 10924 & 2136 & 6 & 61 & 23316 & 3331 & 5 & 55 & 19775 & 2997 \\
\hline 2003 & 10 & 32 & 11133 & 2394 & 12 & 60 & 23323 & 3693 & 10 & 54 & 18961 & 3605 \\
\hline 2005 & 9 & 32 & 11097 & 2327 & 15 & 57 & 23244 & 4003 & 16 & 52 & 18465 & 3603 \\
\hline 2007 & 9 & 35 & 11203 & 2790 & 16 & 56 & 23089 & 4391 & 26 & 54 & 18466 & 4436 \\
\hline 2009 & 6 & 36 & 11213 & 3866 & 9 & 56 & 23182 & 4381 & 14 & 61 & 19538 & 6017 \\
\hline 2011 & 6 & 36 & 10478 & 3393 & 12 & 61 & 23015 & 4404 & 16 & 64 & 19457 & 6285 \\
\hline
\end{tabular}

Notes: Route - the number of routes operated between two regions; Time [day] - average voyage time; Length [mile] - average voyage length; Size [TEU] - average ship size; ECNA - East Coast North America; WCNA - West Coast North America; MED - the Mediterranean Sea. 
The pendulum was the second most common pattern. In reality, almost all shipping lines in the top 20 involved in the pattern. From 1995 to 2002, pendulum routes were increasingly deployed and played an important role in the global shipping system. 18 routes contributed to some one third of the total calls (392 weekly calls) and fleet capacity $(0.97 \mathrm{~m}$ TEUs $)$ in 2002 . Some major carriers reserved a big part of their fleet for pendulum services. As a result, the capacity of their pendulum fleet could be comparable with that of ETE one, for example Maersk Line $(0.17 \mathrm{~m}$ vs. $0.23 \mathrm{~m}$ TEUs); Hanjin $(0.2 \mathrm{~m}$ vs. $0.1 \mathrm{~m}$ TEUs); CMA-CGM (0.04m vs. $0.1 \mathrm{~m}$ TEUs). Nevertheless, many pendulum routes were suspended in favour of the ETE system afterwards. In 2011, the ratios between the two segments of these carriers remained solely 1:10, $1: 9$ and $1: 42$, respectively. Overall, merely 8 routes fell into the pendulum and constituted around one tenth of the total calls and fleet capacity.

Of the four pendulum models presented in Section 1.4, the three former ones were always in use. It could be noted the shrink of second-model routes stretching between North America and Asia through the fulcrum of the Mediterranean Sea (Table 4). The phenomenon stemmed from the shift of the easternmost market from NEA, to South East Asia, then South Asia. Forth-model pendulum routes were the longest in the market. They were first in operation between 1997 and 2003 and emerged again from 2009. In the latter period, the ships also sailed between the two seaboards of North America via the Suez
Canal. However, they only visited East Asia but omitted North Europe and the Mediterranean Sea in the middle of the voyage.

The RTW had been expected as a breakthrough in the industry, but its application had been rare. Only Evergreen has successfully employed it for a long time. In the mid-1990s, half of the Taiwanese carrier's East-West fleet capacity was assigned to two long-standing RTW services. However, they have been abandoned and substituted by pendulum and ETE services since 2002. Occasionally, RTW loops had been designed by carriers such as Cho Yang and DSR-Senator (in the 1990s); CSCL, CSAV and Zim (in the mid-2000s); CMA-CGM (from 2009). By 2002, a pair of RTW loops had been often launched simultaneously to serve the global trade on both directions. Nevertheless, shipping lines only preferred either an eastbound or a westbound route at later times.

Between 2000 and 2008, a few triangle routes were launched on the East-West network by Maersk Line, CMA-CGM and CP Ships. The ships often travelled eastwards from East Coast North America to the Mediterranean Sea, then South Asia. Afterwards, they changed the direction to return to the starting range. The journey was more or less the same with that of the pendulum routes to link these regions, but bypassed Mediterranean Sea ports on the westbound leg. A priority of the triangle loops could be to serve increasingly westbound traffic from South Asia to East Coast North America.

Table 4. Operational parameters of pendulum, RTW and triangle routes

\begin{tabular}{|c|c|c|c|c|c|c|c|c|c|c|c|c|}
\hline & \multicolumn{4}{|c|}{ Pendulum 1} & \multicolumn{4}{|c|}{ Pendulum 2} & \multicolumn{4}{|c|}{ Pendulum 3} \\
\hline & Route & Time & Length & Size & Route & Time & Length & Size & Route & Time & Length & Size \\
\hline 1995 & 2 & & 34147 & 2896 & 5 & & 25018 & 2080 & 2 & & 32133 & 2742 \\
\hline 1997 & 4 & & 32797 & 3125 & 2 & & 28126 & 2376 & 3 & & 33173 & 3016 \\
\hline 1999 & 4 & & 32675 & 3440 & 2 & & 29065 & 3017 & 4 & & 34798 & 4097 \\
\hline 2001 & 5 & 90 & 32303 & 3733 & 1 & 91 & 29128 & 2831 & 5 & 88 & 32983 & 4575 \\
\hline 2003 & 4 & 90 & 32803 & 4298 & 2 & 73 & 24906 & 3264 & 6 & 87 & 32915 & 4660 \\
\hline 2005 & 4 & 91 & 32552 & 4432 & 2 & 70 & 22506 & 3457 & 4 & 84 & 31684 & 5023 \\
\hline 2007 & 5 & 88 & 32253 & 4622 & 6 & 59 & 21151 & 4019 & 3 & 86 & 30136 & 5267 \\
\hline 2009 & 5 & 89 & 32271 & 4713 & 4 & 61 & 21612 & 4707 & 2 & 91 & 30833 & 7439 \\
\hline \multirow[t]{3}{*}{2011} & 2 & 91 & 32134 & 4697 & 4 & 64 & 21555 & 4675 & 1 & 98 & 31412 & 5556 \\
\hline & \multicolumn{4}{|c|}{ Pendulum 4} & \multicolumn{4}{|c|}{ RTW } & \multicolumn{4}{|c|}{ Triangle } \\
\hline & Route & Time & Length & Size & Route & Time & Length & Size & Route & Time & Length & Size \\
\hline 1995 & & & & & 4 & & 26489 & 3116 & & & & \\
\hline 1997 & 1 & & 39545 & 3993 & 2 & & 26736 & 3863 & & & & \\
\hline 1999 & 2 & & 39242 & 3727 & 2 & & 26875 & 4108 & & & & \\
\hline 2001 & 2 & 100 & 38722 & 4087 & 2 & 70 & 26626 & 4138 & 1 & 56 & 19098 & 1521 \\
\hline 2003 & 1 & 105 & 39232 & 4253 & & & & & 1 & 49 & 19098 & 2646 \\
\hline 2005 & & & & & 2 & 77 & 27591 & 3506 & 2 & 49 & 18970 & 3961 \\
\hline 2007 & & & & & & & & & 1 & 49 & 19113 & 4366 \\
\hline 2009 & 1 & 98 & 37189 & 6059 & 2 & 77 & 25612 & 4857 & & & & \\
\hline 2011 & 1 & 112 & 37189 & 7763 & 1 & 77 & 26796 & 5015 & & & & \\
\hline
\end{tabular}

Notes: Route - the number of routes in operation; Time [day] - average voyage time; Length [mile] - average voyage length; Size [TEU] - Average ship size. 


\section{Comparative analysis of ETE, pendulum and RTW routes}

In this section, five factors are employed to compare operational characteristics of ETE, pendulum and RTW routes: Multiple trades, Complexity, Multiple calls, Transit time and Ship deployment. The three latter factors stem from the decisions of route design, see more description in Tran, Haasis $(2014 ; 2015 b)$. The factor of Multiple calls measures the average number of ports of call per region. It is the issue of port selection. If more ports are visited in a service, its operators will be closer to final markets in exchange of longer voyage of their fleet. Transit time measures how fast containers can be shipped from origin to destination ports and can be considered as a quality indicator of a shipping service. Ship deployment is the matter of suitable ship capacity. The use of bigger size benefits carriers in terms of lower shipping costs thanks to scale economies. Additionally, two other factors are taken into consideration. The factor of Multiple trades is related to the number of trade regions in a shipping route to show market coverage of the route on the East-West corridor. Complexity is to indicate the scale of a route regarding market coverage, deployed fleet, nautical distance and voyage time.

\subsection{Multiple trades}

An ETE route is mainly dedicated to the trade between its westernmost and easternmost markets. Additionally, more goods flows can be attracted by including intermediate port ranges between the two extreme markets of the route. By 2007, about half of the ETE routes on the East-West

Table 5. Captive trades of RTW and pendulum routes

\begin{tabular}{|l|l|}
\hline \multicolumn{1}{|c|}{ Pattern } & \multicolumn{1}{c|}{ Captive trades } \\
\hline Eastbound RTW & Eastbound global \\
\hline Westbound RTW & Westbound global \\
\hline Pendulum 1 & Trans-Pacific, Trans-Atlantic \\
\hline Pendulum 2 & $\begin{array}{l}\text { Trans-Atlantic, Europe - Asia, Intra Asia, } \\
\text { North America - Middle East, North } \\
\text { America - South Asia }\end{array}$ \\
\hline Pendulum 3 & Trans-Pacific, Europe - Asia, Intra Asia \\
\hline Pendulum 4 & $\begin{array}{l}\text { Global traffic except East Asia - East } \\
\text { Coast North America }\end{array}$ \\
\hline
\end{tabular}

corridor only consisted of two regions. Afterwards, operators tended to extend their market coverage and looked for more throughputs by adding more regions on their services. Consequently, the share of the simple ETE strings moved down in the range between 41 and $43 \%$.

RTW and pendulum routes covered wider geographical scope than ETE ones (Table 5). A greater number of markets can be served, which leads to more region-toregion container flows able to be transported on a single loop. A pair of eastbound and westbound RTW strings can serve all the global East-West traffic. Nearly all the key flows can be shipped by the forth-model pendulum route, except the one between East Asia and East Coast North America (ECNA). In addition to Trans-Atlantic and Europe/Asia trades, the third-model pendulum service can carry the extra ones between ECNA and the Middle East, and South Asia.

Between 1995 and 2011 (Table 6), an ETE ship visited 3.48 regions per route on average, the figures were 7.44 for a pendulum one and 6.7 for a RTW one. The former could only serve 5.5 region-to-region cargo flows, whereas the second 16.31 and the latter 22.67 flows. Thanks to the multiple trades, operators can employ RTW and pendulum ship slots several times. Strong legs can subsidise weak ones (Lim 1996), so the negative effect of any trade variability can be reduced on the whole service. In addition, the combination of various trades on a loop may help carriers to deal better with container imbalance and repositioning as the experience of Evergreen, see more in Lloyd's List (1994).

The integration of a series of consecutive ETE services possibly allows carriers to run a service with smaller fleet commitment due to the saving on total voyage time. In accordance with our estimation (Figure 11), total voyage time of the eastbound and westbound RTW routes were 6 days less than that of separate ETE ones (140 days vs. 146 days), whereas the saving of the fourth-model pendulum one was 8 days (111 days vs. 119 days). The merger of Zim's Trans-Pacific and Asia - Mediterranean loops into a pendulum one in 2001 lowered ship requirement by one unit (Drewry 2001). Carriers may have more incentive to exploit pendulum or RTW routes during the period of tonnage shortage. The strongest use of the pendulum pattern in 2002 seemed to coincide with the aggressive growth of the East-West shipping demand, which was 4 percentage points higher than the growth of the supply.

Table 6. Multiple trades on shipping routes

\begin{tabular}{|l|c|c|c|c|c|c|c|c|c|c|c|}
\cline { 2 - 10 } \multicolumn{1}{c|}{} & 1995 & 1997 & 1999 & 2001 & 2003 & 2005 & 2007 & 2009 & 2011 \\
\hline \multicolumn{8}{|c|}{ The average number of visited regions on a loop } \\
\hline ETE & 3.49 & 3.41 & 3.48 & 3.46 & 3.43 & 3.43 & 3.33 & 3.62 & 3.55 \\
\hline Pendulum & 6.89 & 7.7 & 8.25 & 8.08 & 7.92 & 7.3 & 6.71 & 6.92 & 6.63 & 4 & 6 \\
\hline RTW & 6.75 & 7 & 7.5 & 6.5 & & 6.5 & & 4.83 & 5.65 \\
\hline \multicolumn{8}{|c|}{ The average region-to-region cargo flows served by a loop } \\
\hline ETE & 5.53 & 5.35 & 5.55 & 5.49 & 5.44 & 5.31 & 5.04 & 5.83 & 14.58 & 13.63 \\
\hline Pendulum & 14.89 & 17.1 & 19.42 & 18.77 & 17.85 & 15.6 & 14.07 & 8 & 18 \\
\hline RTW & 23 & 24.5 & 28 & 20.5 & & 22 & & 8 & \\
\hline
\end{tabular}




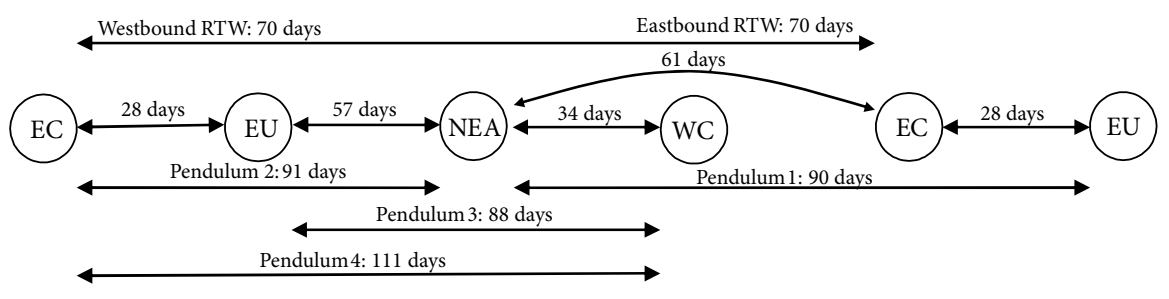

EC: East Coast North America; EU: North Europe; NEA: North East Asia; WC: West Coast North America

Figure 11. Average voyage time of different route patterns in 2001 (EC - East Cost North America; EU - North Europe; NEA - North East Asia; WC - West Coast North America)

\subsection{Multiple calls}

Unlike intercontinental airplanes often calling at a single hub per region, trunk line vessels often pass through more than a stop. As a matter of course, the pure hub and spoke or single regional hub seems to be impractical in container shipping. The decrease of mother vessels' daily cost may not pay off extra feeder and handling cost. Gilman (1999) argues that although transhipment hubs have become more important, their use should not be seen as an alternative of multi-port operation. Network strategies of Maersk Line, Evergreen, Huyndai and MOL, presented by Fremont (2007), Sartini (1999) and Tongzon, Chang (2009), confirm the coexistence of the hub and spoke and multi-port systems to permit extensive market coverage.

Shuttle services operating between two ports have been sometimes launched but with very short lifespan (see more in Drewry 2001, 2010; Visser, Braam 2001). The closest connection makes possible to carry cargo very fast and keep highly reliable service. However, the shuttle routes must rely much upon the two hubs' traffic as well as suffer from ship size's restriction due to small cargo catchment area. In the early 2000s, the ECS high-speed service between Hong Kong and Trieste (Italy) quickly came to an end, chiefly because of poor utilisation levels and lack of customer support (Drewry 2001).

In the years 1995-2011 (Table 7), an East-West route visited 2.84 stops per region on average. Recently, carriers have tended to add more regional calls with the upward trend of the figure from 2.76 in 2007 to 2.99 in 2011. ETE routes were often designed with more calls per region than pendulum and RTW routes. The average amount of the former segment was 2.95 in comparison with 2.71 and 2.69 of the two latter. Fewer visits per region could lead to the saving of voyage time of RTW and pendulum services as displayed in the previous section. According to the simulation of Ashar (1999), ETE routes suffer from

Table 7. Breakdown of average number of calls per region by route patterns

\begin{tabular}{|l|c|c|c|c|c|c|c|c|c|}
\cline { 2 - 10 } \multicolumn{1}{c|}{} & 1995 & 1997 & 1999 & 2001 & 2003 & 2005 & 2007 & 2009 & 2011 \\
\hline ETE & 2.99 & 3.05 & 3 & 2.98 & 2.98 & 2.83 & 2.86 & 3.09 & 3.04 \\
\hline Pendulum & 2.73 & 2.62 & 2.52 & 2.67 & 2.78 & 2.84 & 2.69 & 2.72 & 2.89 \\
\hline RTW & 2.74 & 2.79 & 2.53 & 2.92 & & 2.85 & & 2.63 & 2.67 \\
\hline
\end{tabular}

low slot utilisation on some port-to-port links, which could be as small as $36 \%$ of the ship capacity, due to the multi-ports of call. On the other hand, they benefit from closer proximity to hinterland than the other two, which brings about lower transhipment/distribution costs as well as higher possibility of regional traffic accumulation.

\subsection{Complexity}

Pendulum and RTW routes are surely much more complicated than ETE ones. The complication can be demonstrated through the operation in multiple port ranges, the inclusion of a large number of ports of call, the long voyage distance and time (Tables 6,8 ). As a consequence, high investment and extremely broad service network are prerequisites to phase the pendulum and RTW strings into operation. In 1984, Evergreen spent about $\$ 1 \mathrm{~b}$ to open two RTW services (Transport 2000, 1985), whereas it cost US Lines approximately $\$ 570 \mathrm{~m}$ to build the RTW fleet (Gibney 1987). In 2011, the longest pendulum route required a fleet of 16 ships. Any investment mistake possibly leads to a serious consequence as the case of US Lines.

Maintaining service reliability is a real challenge on RTW and pendulum services because their ships travel through many ports, trade lanes, traffic-crowded sea passages, and different weather conditions. The ships confront higher risks of delay and face more problems than ETE ships to keep schedule. In a survey of American Shipper and the Marine Exchange, out of 8 RTW voyages of Evergreen, only 6 ones arrived at the port of Los Angeles or Long Beach on time, whereas all ETE voyages were punctual (Heaney 2000). Pendulum services was claimed to fall out of favour in 2007 because port congestion made them difficult to follow the schedule.

\subsection{Transit time}

Apart from cost factor, port-to-port transit time is another one influencing on service competitiveness. It is determined not only by operating speed of ships deployed but also by route configuration. Based on the ship schedule, it is possible to estimate transit time from a port to another one by a specific route, then average transit time by each pattern. For example, in 2001, the average transit times from Hong Kong to Los Angeles of the ETE, pendulum and RTW routes were 14.1, 17 and 19 days, respectively. 
Table 8. Scale comparison between ETE, pendulum and RTW routes

\begin{tabular}{|c|c|c|c|c|c|c|c|c|c|}
\hline & 1995 & 1997 & 1999 & 2001 & 2003 & 2005 & 2007 & 2009 & 2011 \\
\hline \multicolumn{10}{|c|}{ The average number of calls per loop } \\
\hline ETE & 10.45 & 10.41 & 10.44 & 10.31 & 10.21 & 9.7 & 9.5 & 11.17 & 10.8 \\
\hline Pendulum & 18.78 & 20.2 & 20.75 & 21.54 & 22 & 20.7 & 18.07 & 18.83 & 19.13 \\
\hline RTW & 18.5 & 19.5 & 19 & 19 & & 18.5 & & 10.5 & 16 \\
\hline \multicolumn{10}{|c|}{ The average length per loop [mile] } \\
\hline ETE & 16634 & 16560 & 16255 & 16332 & 16621 & 16901 & 16908 & 17485 & 17475 \\
\hline Pendulum & 28628 & 32651 & 33876 & 33308 & 32135 & 30196 & 27042 & 28888 & 27387 \\
\hline RTW & 26489 & 26736 & 26876 & 26627 & & 27592 & & 25613 & 26796 \\
\hline \multicolumn{10}{|c|}{ The average time per loop [day] } \\
\hline ETE & & & & 43.21 & 44.62 & 44.61 & 44.49 & 49.62 & 52.99 \\
\hline Pendulum & & & & 91.23 & 87.54 & 84 & 75.5 & 81.08 & 81.25 \\
\hline RTW & & & & 70 & & 77 & & 56 & 77 \\
\hline
\end{tabular}

Table 9. Transit time between ports [days]

\begin{tabular}{|c|c|c|c|c|c|c|c|c|c|c|c|c|}
\hline & \multicolumn{2}{|c|}{2001} & \multicolumn{2}{|c|}{2003} & \multicolumn{2}{|c|}{2005} & \multicolumn{2}{|c|}{2007} & \multicolumn{2}{|c|}{2009} & \multicolumn{2}{|c|}{2011} \\
\hline Direction & EB & WB & EB & WB & EB & WB & $\mathrm{EB}$ & WB & EB & WB & $\mathrm{EB}$ & WB \\
\hline \multicolumn{13}{|c|}{ Hong Kong - Los Angeles } \\
\hline ETE & 14.1 & 18 & 14.4 & 19.3 & 14 & 19.7 & 14.2 & 21.2 & 16.1 & 18.9 & 15.6 & 20.8 \\
\hline Pendulum & 17 & 20 & & 18 & 12 & 16.5 & 15 & 18.7 & 15 & 19.5 & & 20 \\
\hline RTW & 19 & 20 & & & & & & & & & & \\
\hline \multicolumn{13}{|c|}{ New York - Rotterdam } \\
\hline ETE & 11 & 9.5 & 11.5 & 10 & 16.7 & 10 & 16.3 & 11.8 & 15.5 & 12.5 & 17.7 & 12.7 \\
\hline Pendulum & 11 & 9.75 & 11.3 & 9.7 & 11.7 & 9.7 & 12 & 9.5 & 11.5 & 10 & 13.5 & 9 \\
\hline RTW & & 14 & & & & & & & & & & \\
\hline \multicolumn{13}{|c|}{ Hong Kong - Rotterdam } \\
\hline ETE & 27.9 & 22.9 & 27.4 & 23.1 & 29.5 & 23.7 & 28.9 & 25 & 31.1 & 27.2 & 34.7 & 29.1 \\
\hline Pendulum & 25 & 25 & 27.3 & 23.5 & 27 & 24.5 & & & & & & \\
\hline RTW & & 21 & & & & & & & & & & \\
\hline \multicolumn{13}{|c|}{ Hong Kong - New York (via the Panama Canal) } \\
\hline ETE & 29 & 34 & 28.1 & 33 & 25.4 & 31.3 & 25.4 & 31.3 & 27.5 & 33.2 & 28.3 & 36.7 \\
\hline Pendulum & 32.9 & 36.8 & 33.8 & 37.8 & 33 & 33.3 & 31 & 33.3 & 30.8 & 34.2 & 31 & 37.7 \\
\hline RTW & 34 & 36 & & & 31 & 32 & & & 26 & 30 & 36 & \\
\hline
\end{tabular}

Notes: EB - eastbound; WB - westbound.

Because of a small number of RTW routes in operation between 2001 and 2011 (Table 9), only 554 samples were collected to compare average transit time between ETE and RTW routes. The former was more time-competitive than the latter in $64 \%$ of the total samples. Concerning the comparison between ETE and pendulum routes, the latter had faster transit time in $55 \%$ of 5502 port-to-port flows gathered. In particular, pendulum routes had strong advantage on the Trans-Atlantic trade lanes with the ratio of $74 \%$ and Trans-Pacific ones with the ratio of $59 \%$. Such advantages could stem from fewer ports of call per region, leading to faster connection between the two adjacent regions on the East-West axis. In contrast, ETE routes provided quicker transportation on NEA - East Coast North America (61\% of the samples) and had slight time advantage on Europe - NEA routes (52\%). The fact that the pendulum route often consists of many port ranges leads to the detour of some cargo flows. For instance, the pendulum ship could deviate to the West Coast North America instead of directly linking NEA and East Coast North America as the ETE ship. As a result, the transit time could become longer.

\subsection{Ship deployment}

Deploying big vessels has become an important strategy of liner carriers so as to reap cost saving. The largest container ship was 4300 TEUs in 1988, then 7100 TEUs in 1996, 15500 TEUs in 2006, and is more than 18000 TEUs now (Tran, Haasis 2015a). The trend happened most substantially on ETE routes between 1995 and 2011. Noticeably, the mean sizes on North Europe - NEA, Mediterranean Sea - NEA and NEA - West Coast North America routes climbed by 2.67 times (from 3443 to 9188 TEUs), 3.01 times (from 2983 to 6285 TEUs) and 2.61 times (from 2905 
to 6341 TEUs), correspondingly. The biggest ships in the market have been often launched on the former segment. The growth on the Trans-Atlantic routes was much smaller by merely 1.41 times (from 2806 to 3930 TEUs). Though there was no geographical restriction on vessel capacity as NEA - East Coast North America routes, the sluggish traffic and short voyage distance have squeezed shipping lines out of investing in large ships on the corridor.

In the mid-1990s, pendulum and RTW loops could be comparable to ETE ones related to ship size. Nevertheless, they have become more and more disadvantageous in consequence of the invasion of mega vessels on the key ETE loops. From 1995 to 2011 (Table 10), the average capacity of ETE routes went up by 2.22 times, whilst the respective rates of pendulum and RTW ones were 2.05 and 1.61. The largest size on the former sector obtained 15550 TEUs in 2011, whereas those on the two latter sectors were just 8533 TEUs and 5100 TEUs, correspondingly.

The first factor restricting the influx of big ships on pendulum and RTW loops has been the constraint of the Panama Canal. It does not allow the use of Post-Panamax ships on RTW and first-model pendulum strings. The second factor has been traffic discrepancy between different trade lanes. As it is shown in Figure 12, the ratio between the volume on the Trans-Atlantic corridor and that on the Europe - East Asia or Trans-Pacific was less than one third. Mega vessels could be economical on the two latter corridors, but subjected to serious under-utilisation on the former one. Load factor on the eastbound leg of the Trans-Atlantic trade lane could be merely one fifth of that on the westbound leg of the Europe - East Asia lane or the eastbound leg of the Trans-Pacific lane.

Some studies have expected the employment of pendulum and RTW ones as the backbones of the global shipping (Ashar 1999, 2000, 2002; Visser, Braam 2001). Nevertheless, economics of ship size will be still an obstacle for their ideas. Whereas the Panama Canal's restriction will be solved soon thanks to the expansion project, the trade dissimilarity between the key legs will certainly remain a challenge for operators to place big vessels on RTW and pendulum routes.

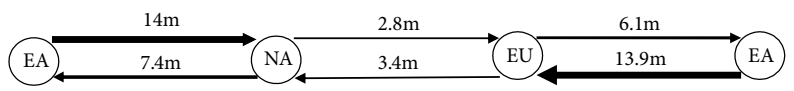

Figure 12. Traffic imbalance between the key legs (EA - East Asia; NA - North America; EU - Europe) (Drewry 2012)

\section{Conclusions}

This article takes into account-deployed patterns of transcontinental shipping routes on the East-West corridor between 1995 and 2011. The majority of routes operated under the ETE pattern. The pendulum pattern was the second favourite in the market, but the use became declined in the 2000s. The RTW had been not applied popularly. Evergreen had been the sole operator capable of employing the pattern for a long period. The triangle had occasionally appeared in the industry.

Integration of multi-trades is obviously an important advantage of the pendulum and RTW patterns, which facilitates the consolidation of containers from many markets. Additionally, the integration could help operators to reduce the number of ships commitment to the service in comparison with separate ETE routes thanks to shorter voyage time.

ETE routes often consisted of more ports of call per region than the other two ones, which could be their advantage in terms of hinterland proximity. On the other hand, they could suffer from higher cost of arterial vessels and under-utilisation on some regional port-to-port links.

In terms of scale, the pendulum and RTW were evidently much more complex than the ETE regarding the number of regions of call, ports of call, voyage distance and time. Consequently, operators were subjected to high investment and more of a challenge to keep service reliability.

In respect of transit time, RTW routes seemed to be less competitive than ETE ones. There were no big differences between pendulum and ETE ones. The advantage of the former often existed on the pairs of ports located in two adjacent regions. On the other hand, the advantage shifted to the side of ETE ones when the flows were subjected to deviation of ship journey because of intermediate calls between the original and final markets.

The deployment of mega vessels was restricted on pendulum and RTW routes. The first reason is caused by the nautical limitation of the Panama Canal. The second one came from traffic discrepancy between the key trade lanes, resulting in low slot usage on some legs.

Our article has approached a vacancy in network research in container liner shipping. It may be the first one to comprehensively survey the application of operational patterns on route design in the industry. Based on the empirical work, operational parameters as well as the

Table 10. Ship deployment

\begin{tabular}{|c|c|c|c|c|c|c|c|c|c|c|}
\hline & & 1995 & 1997 & 1999 & 2001 & 2003 & 2005 & 2007 & 2009 & 2011 \\
\hline \multirow{2}{*}{ ETE } & AS & 3019 & 3325 & 3449 & 3757 & 4146 & 4460 & 5190 & 6156 & 6708 \\
\hline & LS & 4950 & 6000 & 6690 & 7500 & 8063 & 9200 & 12513 & 13800 & 15550 \\
\hline \multirow{2}{*}{ Pendulum } & AS & 2581 & 3027 & 3723 & 4045 & 4330 & 4506 & 4604 & 5372 & 5312 \\
\hline & LS & 4072 & 4545 & 6600 & 6600 & 6600 & 6600 & 6611 & 9200 & 8533 \\
\hline \multirow{2}{*}{ RTW } & AS & 3116 & 3863 & 4108 & 4138 & & 3506 & & 4857 & 5015 \\
\hline & LS & 4229 & 4229 & 4211 & 4229 & & 4253 & & 5624 & 5100 \\
\hline
\end{tabular}

Notes: AS - average ship size [TEU]; LS - largest ship size [TEU]. 
strength and weakness of the ETE, pendulum and round the world patterns have been partly demonstrated.

There are still some limitations in our work, which can raise questions for the future research. The data is only limited until 2011, so the updated one should be taken into account to investigate new trends in the shipping industry. This research is more descriptive, the next steps should develop quantitative models to evaluate the efficiency of the operational patterns regarding cost, profit, slot utilization and empty container repositioning. Finally, the extension of the Panama Canal will remove its restriction related to ship size, which will lead to the concern about the viability of the RTW pattern and some pendulum ones in serving the global market.

\section{References}

Angeloudis, P.; Bichou, K.; Bell, M. G. H. 2007. Security and reliability of the liner container-shipping network: analysis of robustness using a complex network framework, in K. Bichou, M. G. H. Bell, A. Evans (Eds.). Risk Management in Port Operations, Logistics and Supply Chain Security, London, 95-106. https://doi.org/10.4324/9781315850504

Ashar, A. 2002. Revolution now, Containerisation International (January): 56-59.

Asahr, A. 2000. 2020 vision, Containerisation International (January): 35-39.

Ashar, A. 1999. The fourth revolution, Containerisation International (December): 57-61.

Aversa, R.; Botter, R. C.; Haralambides, H. E.; Yoshizaki, H. T. Y. 2005. A Mixed integer programming model on the location of a hub port in the east Coast of South America, Maritime Economics \& Logistics 7(1): 1-18. https://doi.org/10.1057/palgrave.mel.9100121

Baird, A. J. 2006. Optimising the container transhipment hub location in Northern Europe, Journal of Transport Geography 14(3): 195-214.

https://doi.org/10.1016/j.jtrangeo.2004.12.004

Boyes, J. R. C. 1985. Yangming prepares to swing into action with pendulum service, Containerisation International (August): 30-33.

Chen, C.; Zeng, Q. 2010. Designing container shipping network under changing demand and freight rates, Transport 25(1): 46-57. https://doi.org/10.3846/transport.2010.07

Chineseshipping. 2011. Grand China Bundles SPX and TPX Loops into California Butterfly Service. Available from Internet: http://www1.chineseshipping.com.cn/en/news/newsinfo. jsp?id=265551

CI. 2012. Containerisation International Yearbook 2012. Containerisation International (CI). Informa Publisher.

CI. 2011. Containerisation International Yearbook 2011. Containerisation International (CI). Informa Publisher.

CI. 2010. Containerisation International Yearbook 2010. Containerisation International (CI). Informa Publisher.

CI. 2009. Containerisation International Yearbook 2009. Containerisation International (CI). Informa Publisher.

CI. 2008. Containerisation International Yearbook 2008. Containerisation International (CI). Informa Publisher.

CI. 2007. Containerisation International Yearbook 2007. Containerisation International (CI). Informa Publisher.

CI. 2006. Containerisation International Yearbook 2006. Containerisation International (CI). Informa Publisher.
CI. 2005. Containerisation International Yearbook 2005. Containerisation International (CI). Informa Publisher.

CI. 2004. Containerisation International Yearbook 2004. Containerisation International (CI). Informa Publisher.

CI. 2003. Containerisation International Yearbook 2003. Containerisation International (CI). Informa Publisher.

CI. 2002. Containerisation International Yearbook 2002. Containerisation International (CI). Informa Publisher.

CI. 2001. Containerisation International Yearbook 2001. Containerisation International (CI). Informa Publisher.

CI. 2000. Containerisation International Yearbook 2000. Containerisation International (CI). Informa Publisher.

CI. 1999. Containerisation International Yearbook 1999. Containerisation International (CI). Informa Publisher.

CI. 1998. Containerisation International Yearbook 1998. Containerisation International (CI). Informa Publisher.

CI. 1997. Containerisation International Yearbook 1997. Containerisation International (CI). Informa Publisher.

CI. 1996. Containerisation International Yearbook 1996. Containerisation International (CI). Informa Publisher.

Container Insight. 1988. Ming pendulum, Container Insight (January): 8-9.

Cullinane, K.; Khanna, M. 2000. Economies of scale in large containerships: optimal size and geographical implications, Journal of Transport Geography 8(3): 181-195. https://doi.org/10.1016/S0966-6923(00)00010-7

De Monie, G. 2001. Re-evaluating the economics of transshipment, in TOC 2001: Terminal Operations Conference, 20 June 2001, Lisbon, Portugal.

Drewry. 2013. Annual Container Market Review and Forecast. Drewry Shipping Consultants Publisher, London.

Drewry. 2012. Annual Container Market Review and Forecast. Drewry Shipping Consultants Publisher, London.

Drewry. 2004. Annual Container Market Review and Forecast. Drewry Shipping Consultants Publisher, London.

Drewry. 2001. Annual Container Market Review and Forecast. Drewry Shipping Consultants Publisher, London.

Drewry. 2000. Annual Container Market Review and Forecast. Drewry Shipping Consultants Publisher, London.

Drewry. 1986. Traffic and Competition on Round-the-World Container Routes. Drewry Shipping Consultants, London.

Ducruet, C. 2013. Network diversity and maritime flows, Journal of Transport Geography 30: 77-88. https://doi.org/10.1016/j.jtrangeo.2013.03.004

Dynamar. 2007. Transhipment \& Feedering: Trades, Operators, Ships, Dynamar B.V., Alkmaar, Netherlands. 15 p. Available from Internet: https://www.dynamar.com/system/table_of_contents/1/original/Feedering\%202007\%20-\%20Contents\%20Overview\%20and\%20Preface.pdf

Fleming, D. K. 2010. Patterns of international ocean trade, in C. Grammenos (Ed.). The Handbook of Maritime Economics and Business, 67-98. https://doi.org/10.4324/9780203721636

Fleming, D. K. 2000. A geographical perspective of the transhipment function, International Journal of Maritime Economics 2(3): 163-176. https://doi.org/10.1057/ijme.2000.15

Frankel, E. G. 2004. The future of containerization, IAME 2004: Annual Conference of the International Association of Maritime Economists, 30 June-2 July 2004 Izmir, Turkey.

Fremont, A. 2007. Global maritime networks: the case of Maersk, Journal of Transport Geography 15(6): 431-442. https://doi.org/10.1016/j.jtrangeo.2007.01.005

Gardiner, P. 1998. The Liner Market 1997/98: New Alliances and the New Era. London: Lloyds of London Press. 
Gelareh, S.; Maculan, N.; Mahey, P.; Monemi, R. N. 2013. Huband-spoke network design and fleet deployment for string planning of liner shipping, Applied Mathematical Modelling 37(5): 3307-3321.

https://doi.org/10.1016/j.apm.2012.07.017

Gibney, R. F. 1987. McLean - v-the Rest. US Lines's Jumbo R$T$-W Gamble Fails - Impact on the Mainstream Market. Container Insight Publisher. 35 p.

Gielessen, H. G. 1991. Port selection - a round the world (RTW) container liner perspective, in R. G. Stuchtey (Ed). Port Management Text Book - Volume 3: Port Marketing. ISL Publisher, 213-230.

Gilman, S. 1999. The size economies and network efficiency of large containerships, International Journal of Maritime Economics 1(1): 39-59. https://doi.org/10.1057/ijme.1999.4

Gouvernal, E.; Debrie, J.; Slack, B. 2005. Dynamics of change in the port system of the western Mediterranean, Maritime Policy \& Management: the Flagship Journal of International Shipping and Port Research 32(2): 107-121.

https://doi.org/10.1080/03088830500083539

Hanjin Shipping. 2016. Hanjin Shipping Co. Ltd. Available from Internet: http://www.hanjin.com

Heaney, S. 2000. Reliability vs. cost, American Shipper (October): 68-69.

Imai, A.; Nishimura, E.; Papadimitriou, S.; Liu, M. 2006. The economic viability of container mega-ships, Transportation Research Part E: Logistics and Transportation Review 42(1): 21-41. https://doi.org/10.1016/j.tre.2004.07.002

Kim, C. K. 1987. An Innovation in Liner Shipping: the Roundthe-World Service as a Global Strategy. Institute of Shipping Economics and Logistics, Bremen. $150 \mathrm{p}$.

Knee, R. 1987. Senator line begins RTW service, American Shipper (July): 12-13.

Konings, J. W. 2006. Market development in container barge transport by means of hub-and-spoke networks, in J. O. Puig, R. M. Barbé, V. G. Carcellé (Eds.). Maritime Transport III, $109-129$.

Lim, S.-M. 1996. Round-the-world service: the rise of evergreen and the fall of U.S. lines, Maritime Policy \& Management: the Flagship Journal of International Shipping and Port Research 23(2): 119-144.

https://doi.org/10.1080/03088839600000070

Lim, S.-M. 1994. Economies of container ship size: a new evaluation, Maritime Policy \& Management: the Flagship Journal of International Shipping and Port Research 21(2): 149-160. https://doi.org/10.1080/03088839400000031

Lloyd's List. 1994. Evergreen. Round-the-world service ... ten years on. Lloyd's of London Press. 48 p.

Ma, S. 2006. Maritime Economics. Unpublished lecture handout. World Maritime University, Malmo, Sweden.

McCalla, R. J. 2008. Container transshipment at Kingston, Jamaica, Journal of Transport Geography 16(3): 182-190. https://doi.org/10.1016/j.jtrangeo.2007.05.006

Notteboom, T. E. 2012. Towards a new intermediate hub region in container shipping? Relay and interlining via the Cape route vs. the Suez route, Journal of Transport Geography 22: 164-178. https://doi.org/10.1016/j.jtrangeo.2012.01.003

Stenvert, R.; Penfold, A. 2007. Container Port Strategy: Emerging Issues. Ocean Shipping Consultants Ltd. $142 \mathrm{p}$.

Pearson, R.; Fossey, J. 1983. World Deep-Sea Container Shipping: A Geographical, Economic and Statistical Analysis. Gower Pub Co. 288 p.
Robinson, R. 1998. Asian hub/feeder nets: the dynamics of restructuring, Maritime Policy \& Management: the Flagship Journal of International Shipping and Port Research 25(1): 21-40. https://doi.org/10.1080/03088839800000043

Rodrigue, J.-P.; Comtois, C.; Slack, B. 2009. The Geography of Transport Systems. 2nd edition. Routledge. 368 p.

Sartini, N. 1999. Transhipment versus direct ports, in TOC 1999: Terminal Operations Conference, 1-3 June 1999, Genova, Italy.

Slack, B. 1999. Intermodal transportation, in B. S. Hoyle, R. Knowles (Eds.). Modern Transport Geography, 263-289.

SOL. 2008. Evergreen to Offer Butterfly Loop on Asia - US Trade. Shipping OnLine Inc. Available from Internet: http://www. shippingonline.cn/news/newsContent.asp? $\mathrm{id}=4782$

Sutcliffe, P.; Ratcliffe, B. 1995. The battle for med hub role, Containerisation International (July): 95-99.

Tongzon, J. L.; Chang, Y. T. 2009. Hub and spoke networks versus direct shipments, in IAME 2009: Annual Conference of the International Association of Maritime Economists, 24-26 June 2009, Copenhagen, Denmark.

Tran, N. K. 2011. Studying port selection on liner routes: An approach from logistics perspective, Research in Transportation Economics 32(1): 39-53.

https://doi.org/10.1016/j.retrec.2011.06.005

Tran, N. K.; Haasis, H.-D. 2014. Empirical analysis of the container liner shipping network on the East-West corridor (1995-2011), Netnomics: Economic Research and Electronic Networking 15(3): 121-153. https://doi.org/10.1007/s11066-014-9088-x

Tran, N. K.; Haasis, H.-D. 2015a. An empirical study of fleet expansion and growth of ship size in container liner shipping, International Journal of Production Economics 159: 241-253. https://doi.org/10.1016/j.ijpe.2014.09.016

Tran, N. K.; Haasis, H.-D. 2015b. Literature survey of network optimization in container liner shipping, Flexible Services and Manufacturing Journal 27(2-3): 139-179. https://doi.org/10.1007/s10696-013-9179-2

Tran, N. K.; Haasis, H.-D.; Buer, T. 2017. Container shipping route design incorporating the costs of shipping, inland/feeder transport, inventory and $\mathrm{CO}_{2}$ emission, Maritime Economics \& Logistics 19(4): 667-694. https://doi.org/10.1057/mel.2016.11

Transport 2000. 1985. The Evergreen dynasty begins, Transport 2000 (January): 30-32.

UNCTAD. 2009. Transport Newsletter. No 43. United Nations Conference on Trade and Development (UNCTAD).

Visser, D.; Braam, T. B. C. 2001. Liner Trade 2020 - Vision of a Huge Global Operation, in DYNAMAR (Ed.). Liner Shipping 2020, Dynamar B.V., Alkmaar, Netherlands, 69-82.

Vrenken, H.; Macharis, C.; Wolters, P. 2005. Intermodal Transport in Europe. European Intermodal Association, Brussels. $267 \mathrm{p}$.

Wang, J. J.; Slack, B. 2000. The evolution of a regional container port system: the Pearl River delta, Journal of Transport Geography 8(4): 263-275.

https://doi.org/10.1016/S0966-6923(00)00013-2

Willmington, R. 2004. When US lines timed out, Fairplay (December): 40-40.

ZIM. 2016. ZIM Integrated Shipping Services Ltd. Available from Internet: http://www.zim.com 